\title{
Fatigue in industry
}

\author{
E. GRANDJEAN
}

From the Institut für Hygiene und Arbeitsphysiologie, Eidgenössische Technische Hochschule, CH-8092 Zürich, Switzerland

ABSTRACT Physical fatigue is a painful phenomenon which is localised in overstressed muscles. Mental fatigue is a diffuse sensation of weariness; it is a functional state, one of several intermediate conditions between the two extremes of alarm and sleep. A neurophysiological model of fatigue, involving an activating and inhibitory system has been developed. Fatigue in industrial practice has clinical symptoms: psychic instability, fits of depression and increased liability to illness. Indicators of fatigue are work performance, subjective feelings of fatigue, electroencephalography, flickerfusion frequency and various psychomotor and mental tests. Several field studies do, to some extent, confirm the above-mentioned concept of fatigue.

Fatigue is a state that is familiar to all of us in everyday life. The term usually denotes a loss of efficiency, and a disinclination for any kind of effort, but it is not a single, definite state. Nor does it become clearer if we define it more closely, as physical fatigue, mental fatigue, and so on. The term fatigue has been used in so many different senses that its applications have become almost chaotic. Nevertheless the common division into physical (or muscular) fatigue and mental fatigue is a reasonable distinction. The former is an acutely painful phenomenon, which arises in overstressed muscles and is localised there. Mental fatigue, in contrast, is a diffuse sensation which is accompanied by feelings of indolence and disinclination for any kind of activity. These two forms of fatigue arise from completely different physiological processes, and must be discussed separately.

\section{Muscular fatigue}

Figure 1 illustrates the external signs of muscular fatigue as they appear in an experiment with an isolated muscle from a frog. The muscle is stimulated electrically, causing it to contract and perform physical work by lifting a weight. After several seconds it is seen that:

(1) the height of lift decreases;

(2) both contraction and relaxation become slower;

(3) the latency (interval between stimulation and beginning of the contraction) becomes longer.

Received for publication 13 November 1978

Accepted for publication 5 March 1979

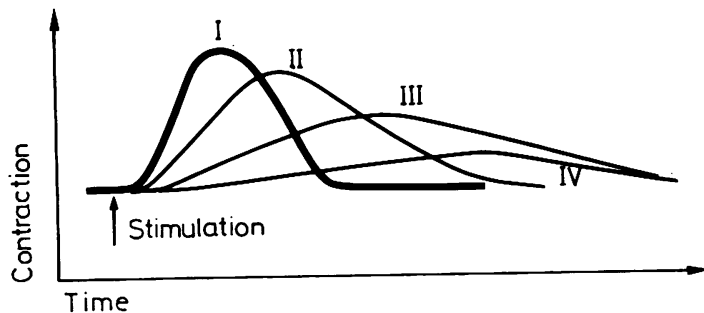

Fig. 1 Physical manifestations of fatigue in an isolated muscle from a frog's leg. $I=$ contraction and relaxation of a fresh muscle; II = the same, after moderate stress; $I I I=$ the same, after heavy stress; IV = the same, after very severe stress.

The performance of the muscle falls off with increasing strain until the stimulus no longer produces a response. Human beings show this process, whether the nerve or muscle is stimulated electrically, or whether the research subject makes voluntary and rhythmical contractions of a muscle over a period. This phenomenon of reduced performance of a muscle after stress is called muscular fatigue in physiology, and is characterised not only by reduced power but also by slower movement. Herein lies the explanation of the impaired co-ordination and increased liability to errors and accidents that accompany muscular fatigue.

\section{BIOCHEMICAL CHANGES}

We know that during muscular contraction chemical processes occur which, among other things, provide the energy necessary for mechanical effort. After 
contraction, while the muscle is relaxed and resting, the energy reserves are replenished. Thus both energy-releasing breakdown, and energy-restoring synthesis are occurring in a working muscle. If the demand for energy exceeds the powers of regeneration, the metabolic balance is upset, resulting in a loss of muscular performance.

After a muscle has been heavily stressed its energy reserves (sugar and phosphorus compound) are depleted, while waste products multiply, the most important of these being lactic acid and carbon dioxide. The muscular tissue becomes more acid.

\section{ELECTROPHYSIOLOGICAL PHENOMENA}

There are many references in the literature to the fact that, even after a muscle has been exhausted by repeated voluntary contractions, it will still respond to an electrical stimulus applied through the skin, suggesting that this form of fatigue is a phenomenon of the central nervous system, not of the muscle itself. This interpretation cannot, however, be confirmed in every case. Many physiologists have observed that, when the muscle itself is in an exhausted state, it does not contract any more, even though further motor nerve impulses are visible on the electromyogram. It seems that fatigue has now become a peripheral phenomenon affecting the muscle fibres, as Scherrer (1967) suggests. We must assume that one group of observers was looking for the first sign of fatigue, whereas the other group was studying muscles that were already in a state of exhaustion.

ELECTROMYOGRAMS OF FATIGUED MUSCLE Comparing all the experimental results, we are led to the assumption that the central nervous system acts as a compensatory mechanism during the early stages of fatigue. Thus many electromyographic studies have shown that, when a muscle is repeatedly stimulated, its electrical activity increases even though its contractions remain at the same level, or decline. This must mean that more and more of its individual fibres are being stimulated into action (recruiting of motor units). The electromyogram in Figure 2 demonstrates this increasing electrical activity as fatigue increases.

These electromyographic phenomena have also been observed under practical conditions. For example, after periods of 60-80 minutes perforating punched cards, increased electrical activity was recorded in the muscles of forearms and shoulders of the subjects involved (Yllö, 1962). It is reasonable to conclude from this that the muscular fatigue that arises in industry is still at the stage where it can be compensated for by increased activity of the central nervous system (CNS).

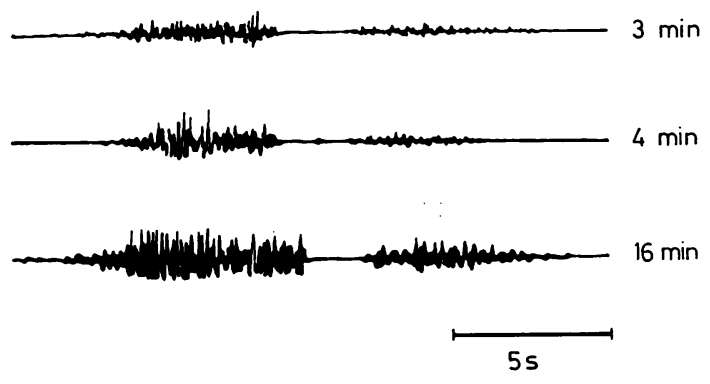

Fig. 2 Three tracings from the electromyogram of the extensor muscle of the upper arm, fatigued by a long series of contractions of equal strength. Shown after 2, 4 and 16 minutes work. Redrawn after Scherrer (1967).

THEORIES. OF MUSCLE FATIGUE

There are essentially only two current theories of muscular fatigue: chemical, and CNS. The former sees the loss of performance in fatigued muscle as a result of chemical processes (consumption of energyproducing substances and accumulation of waste products) with the electrical phenomena in the muscles and nerves playing only a secondary part. In contrast, the CNS theory regards the chemical processes as merely the releasing stimulus for sensory impulses which travel along the nerves to the brain and cerebral cortex. It is here that muscular fatigue makes itself evident as a sensation of weariness. In addition, the afferent impulses inhibit that centre of the brain responsible for motor control of movements, and thus bring about a reduction in the number and frequency of impulses along the motor neurones. This in turn produces the external signs of muscular fatigue, namely the reduction in muscle power and, where rhythmic movements are concerned, shortening and retardation of muscle travel. Neither of these two theories explains everything. All that can be said with certainty is that both CNS phenomena (recruiting of motor neurones) and chemical processes in the muscles (depletion of energy reserves and accumulation of waste products) contribute something to muscular fatigue. Just how the two processes are linked together is not fully understood and requires further experiments and speculation.

\section{Mental fatigue}

GENERAL ASPECTS

The major symptom of fatigue is a general sensation of weariness. We feel ourselves inhibited, and our activities are impaired, if not actually crippled. We have no desire for either physical or mental effort; we feel heavy and drowsy. A feeling of weariness is 
not unpleasant if we are able to rest, but it is distressing if we cannot allow ourselves to relax.

It has long been realised, by simple observation, that weariness, like thirst, hunger and similar sensations, is one of nature's protective devices. Weariness discourages us from overstraining ourselves, and allows time for recuperation.

\section{Functional states}

At any moment the human organism is in one particular functional state, somewhere between the extremes of sleep and of a state of alarm. Within this range there are a number of stages, as follows: deep sleep; light sleep, drowsy; weary, hardly awake; relaxed, resting; fresh, alert; very alert, stimulated; in a state of alarm. Seen in this context, mental fatigue is a functional state which grades in one direction into sleep, and in the opposite direction into a relaxed, restful condition.

Indicators of these functional states are seen in the electroencephalogram. Figure 3 shows five records from electroencephalograms, each characteristic of a different functional state of the body. The previous statements have suggested that, for every functional state that we can describe by terms such as 'weary' or 'lively', there should be a distinctive pattern on the electroencephalogram. Unfortunately this is not the case. The patterns shown in Fig. 3 indicate no more than a very rough correspondence between the encephalogram trace and the underlying physiological state. Nevertheless, it has been possible in the last 20 years to make some interesting discoveries about how various functional states are controlled, using electroencephalography in association with electrical stimuli and behaviour studies.

\section{NEUROPHYSIOLOGICAL ASPECTS OF MENTAL FATIGUE}

The reticular activating system

It is well known that the reticular formation controls the degree of alertness, including attention, and readiness for action. Its level of activity is very low during deep sleep, increases when sleep becomes shallow, and rises steeply on awakening. The higher the level of reticular activity, the higher the level of alertness, culminating in a state of alarm.

The activating structures of the reticular formation do not, however, act on their own initiative: they themselves must be activated by afferent nerve stimuli, which come, in the main, from two sources: the conscious sphere of the cerebral cortex and the sense organs. What significance do these two have?

Feed-back control

Nerve tracts coming from the cerebral cortex carry

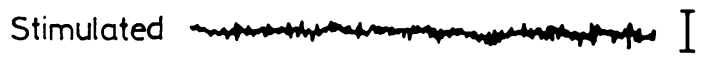

Relaxed

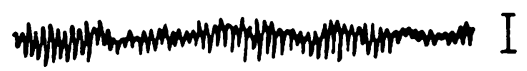

Drowsy
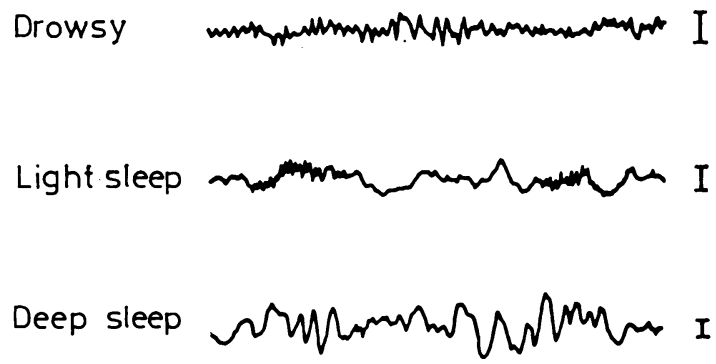

Fig. 3 Five sections from electroencephalograms, characteristic of various functional states. The vertical lines indicate the scale for $1 \mathrm{mV}$. Redrawn after Jasper (1941).

impulses from the conscious sphere into the reticular activating system. Such impulses arise, for example, when an idea or something noticed outside seems ominous and calls for increased alertness. A closed circuit is then set up: the reticular activating system arouses the cerebral cortex and alerts conscious perception. If this results in any significant signals being received, then these stimuli send impulses back along the nerve tracts from the cortex to the reticular activating system. The result is a feed-back system, analogous to that in many electronic devices.

\section{Afferent sensory system}

The other sources of stimuli to the reticular activating system are the stream of afferent stimuli from the sense organs. Nerve fibres branch from all the afferent nerve tracts and pass to the reticular activating system; this sensory inflow affects the level of reticular activity. The importance of this is obvious; signals coming into the body from outside are passed to the reticular activating system and make this more active: this alerts the cerebral cortex and so ensures that the brain is ready to notice and act on what is happening outside the body. This close linkage between the reticular activating system and the afferent sensory system is an essential condition for conscious reaction to the exterior.

Figure 4 shows diagrammatically the flow of stimuli from the cortex and the sense organs to the 


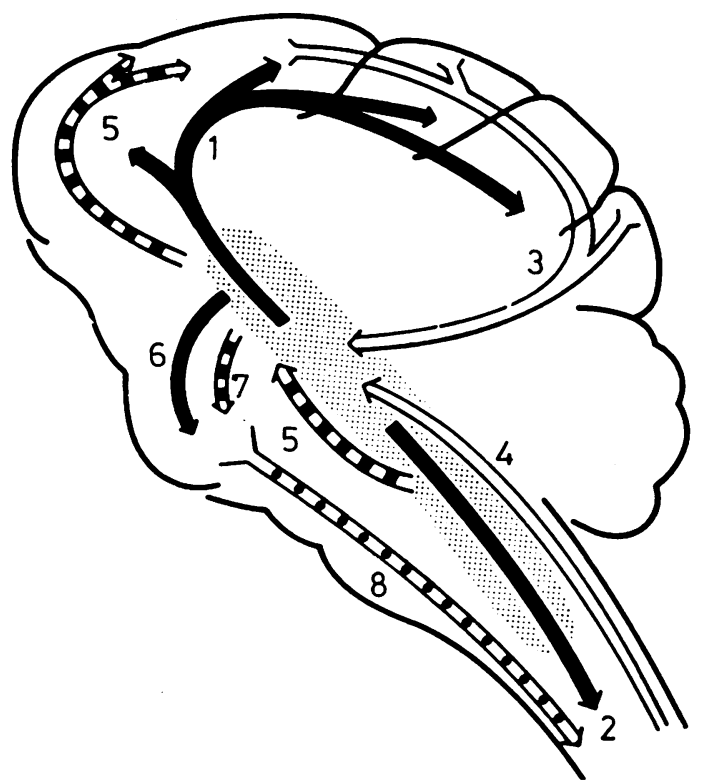

Fig. 4 Diagram illustrating the activating and inhibitory systems in the brain. Dotted area = reticular formation; $I=$ ascending reticular activating system $(A R A S)$; $2=$ descending activating system; 3 = pathways from the cerebral cortex; $4=$ incoming sensory pathways; $5=$ inhibitory (damping) system; 6 and $7=$ links with vegetative (autonomic) centres; $8=$ vegetative tracts of the autonomic nervous system leading to the internal organs.

reticular activating system, as well as the presumed pathways in the cortex itself.

\section{Limbic system and level of activity}

The reticular activating system is not the only nervous organ which affects the state of readiness of the cerebral cortex, and through this, of the entire body. Yet another of the numerous functions of the limbic system must be mentioned: the part it plays in excitement, emotion, and motivation. The general level of alertness is greatly dependent upon the limbic centres for circadian rhythm, fear, rage and tranquillity, as well as for motivation.

\section{Inhibiting system}

These two activating systems are not alone, however, but have other structures which clearly work in opposition to them. In fact many physiologists have conducted experiments showing the existence of nervous elements, both in the interbrain and in the medulla, which have an inhibitory or damping effect on the cerebral cortex. Several authors were able to demonstrate that an inhibition can spread from these struc- tures in the thalamus and extend to the cerebral cortex, and that its effects are evident not only in the animals' behaviour, but also in the electroencephalogram. These inhibiting and sleep-inducing centres collectively constitute a damping system. The working of this damping system is shown diagrammatically by the broken arrows in Figure 4 .

\section{Relation to the autonomic nervous system}

We now know that there are close links between the vegetative (autonomic) nervous system, which controls the activities of the internal organs, and these activating and inhibitory systems. In fact any increase in stimulation of the reticular activating system is accompanied by a series of changes in the internal organs, including an increase in heart rate, a rise in blood pressure, release of more sugar by the liver, and increased metabolism.

By an analogous process, increased activity of the inhibitory system lowers the heart rate and blood pressure, cuts back respiration and metabolism, and relaxes the muscles, while the digestive system works more vigorously to assimilate more energy.

\section{HORMONAL INFLUENCES}

In addition to these purely nervous mechanisms there are also the effects of hormones, which have a part to play in tuning-up the activating system, as well as regulating the sensitivity of the limbic system.

Great importance must be given to the performance hormone adrenaline, which raises the degree of alertness and of the activation level of the body. Bonvallet et al. (1954) deduced what we now know, that every time the activation level is raised by stimuli from outside the body there is a release of adrenaline which, in turn, stimulates activity of the reticular formation. The increased activity from outside stimuli would soon fade away if this hormone did not intervene to maintain it. On this theory, the reticular activating system is responsible for short-term reactions, while effects of longer duration depend upon the action of adrenaline.

It seems, therefore, that the level of activity of the reticular activating system depends upon:

(1) the inflow of sensory stimuli;

(2) the stimulation of the cerebral cortex;

(3) the level of adrenaline.

Much less is known about how the inhibitory system comes under nervous and hormonal control. Nervous mechanisms are poorly understood, and the existence of hormonal factors has been theoretically assumed for many years. The protracted inhibition that occurs during sleep can hardly be represented as a purely nervous mechanism. Moreover, the fact that feelings of weariness disappear after a period of sleep is another reason for supposing that both the onset 
and the continuance of inhibition have a chemical basis.

A few research projects (Legendre and Piéron, 1913; Pappenheimer et al., 1967) have indicated that, if animals are prevented from sleeping, some kind of fatigue substance appears in their cerebrospinal fluid. Both the research and its interpretation are still controversial, however.

In everyday life we are aware that weariness and sleep can result from changes in the content of the blood (such as a fall in the blood sugar level), from many forms of illness, and also from drugs. We still know little, if anything, of the method of operation of these factors on the inhibitory centres in the interbrain and brain stem.

A NEUROPHYSIOLOGICAL MODEL OF FATIGUE Figure 4 illustrates scientifically verified neurophysiological mechanisms. On the basis of these data we can explain how fatigue and its opposite, readiness for action, are regulated. Thus:

(1) fatigue is a functional state, one of several intermediate conditions between the two extremes of alarm and sleep;

(2) functional states are determined by the level of activity of the cerebral cortex, which, in turn, is recognisable by the degree of synchronisation seen in the electroencephalogram (distribution of various frequency ranges among the waves), with the correlated subjective impressions such as 'weary' or 'fresh';

(3) a person's functional state at any particular moment is regulated by the level of activity of various structures in the interbrain and the medulla (brain stem);

(4) there are two types of control structure: those systems that raise the level of activation of the cerebrum, and those that reduce it;

(5) the reticular activating system, and also to some extent certain centres in the limbic system, increase the activation level of the cerebral cortex. If one declines, so does the other;

(6) inhibitory centres in the interbrain and the medulla constitute a damping system, which acts by lowering the activation level of the cerebral cortex.

It follows from points 5 and 6 that the level of cerebral activation, and hence the functional state of the entire organism, is in a state of balance, an equilibrium between the opposing systems of activation and inhibition. If the activating influences predominate, then the organism is placed in a state of increased readiness to react to stimuli, indicated by the physiological signs of freshness, excitement and eager alertness. On the other hand, if inhibitory in-

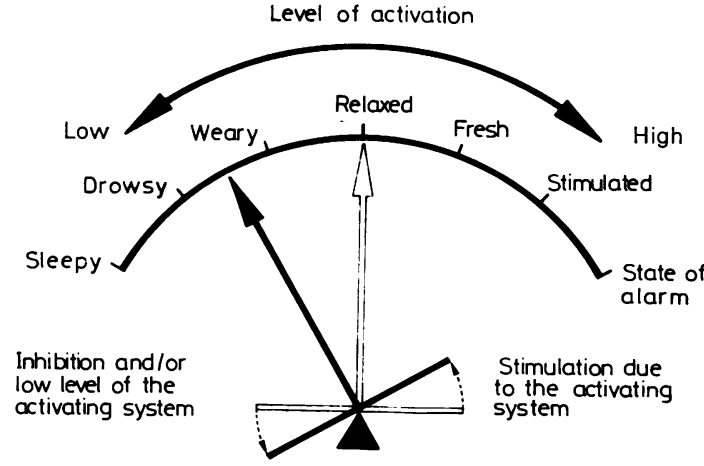

Fig. 5 A theoretical model to illustrate the neurophysiological mechanism which regulates the functional state of the organism. The level of activation of the cerebral cortex, the degree of readiness for action, and the level of alertness all increase from left to right.

fluences predominate, or the activating processes are greatly reduced, then the organism is less ready to react to stimuli, indicated by the physiological signs of weariness and somnolence, accompanied by a lessening of motivation and awareness. This neurophysiological model can be illustrated as a balance (Figure 5).

Our concept can be summarised in different terms, as follows: the level of readiness to act lies somewhere between the two extremes of sleep and the highest state of alarm. Control mechanisms in the medulla and the interbrain regulate this level, and adjust it to meet the momentary demands of the organism. If external influences are dominant then the activating systems prevail: the person feels keyed up, even alarmed, and he is ready for action, both physically and mentally. If, however, inhibiting influences from inside the body predominate, then the damping system prevails: the person feels sluggish, drowsy and lethargic.

\section{Fatigue in industry}

\section{CAUSES AND SYMPTOMS}

We know from everyday experience that fatigue has many different causes, the most important of which can be seen in Figure 6. This shows the degree of fatigue as an aggregate of all the different stresses of the day, in the form of a barrel partly filled with water; the recuperative rest periods would be the outflow from the barrel. To make sure that the barrel does not overflow we must ensure that inflow and outflow are of the same order of magnitude. In other words, to maintain health and efficiency the recuperative processes must cancel out the stresses.

Recuperation takes place mainly during night- 


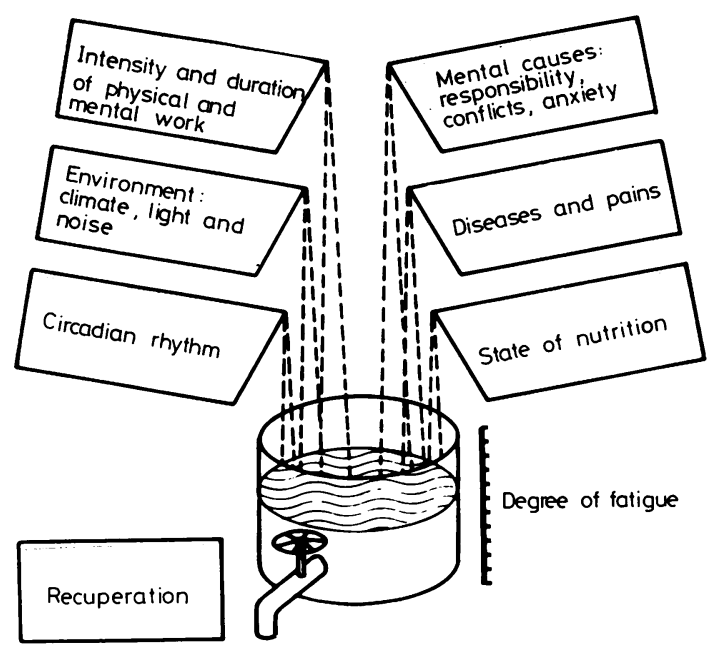

Fig. 6 Theoretical diagram of the combined effect of everyday causes of fatigue, and the recuperation necessary to offset them. The total stresses must be balanced by the total recuperation, within the 24-hour cycle.

time sleep, but free periods during the day, and all kinds of pauses during work, also make their contribution.

It must be emphasised that stress and recuperation must balance over the 24-hour cycle, and that neither of these should be carried over to the next day. If rest is unavoidably postponed until the following evening this can be done only at the expense of wellbeing and efficiency.

Fatigue symptoms are both subjective and objective, the most important being:

(1) subjective feelings of weariness, somnolence, faintness and distaste for work;

(2) sluggish thinking;

(3) reduced alertness;

(4) poor, slow perception;

(5) unwillingness to work;

(6) decline in both bodily and mental performance. Some of these symptoms result in a measurable drop in bodily and mental efficiency.

\section{CLINICAL OR CHRONIC FATIGUE}

Some of the fatigue states that arise in industry are of a chronic nature. These are conditions that are brought about, not by a single instance of overstrain, but by stresses which recur every day, over long periods. Because conditions such as these are usually also accompanied by signs of ill health, this may correctly be called clinical, or chronic fatigue.

Under these conditions the symptoms not only occur during the period of stress, or immediately afterwards, but are more or less latent all the time. Tired feelings are often present on waking, before work has begun. This form of fatigue is often accompanied by feelings of distaste, which have an emotional origin. Such persons often show increased psychic instability (quarrelsomeness and associated behaviour), fits of depression and baseless worries, general weakening of drive and unwillingness to work, and increased liability to illness. Such ailments are mostly vague, and come under the heading of psychosomatic complaints. This term is applied to functional disturbances of the organs or of the circulation, which are judged to be external manifestations of psychological conflicts and difficulties. Some of the commoner of these symptoms are headaches, giddiness, loss of sleep, irregular heart-beat, sudden sweating fits, loss of appetite, and digestive troubles (stomach pains; diarrhoea; constipation). More ailments mean more periods of absence, especially short-term absence, indicating that such absenteeism is attributable to the need for more rest.

People who have psychological problems and difficulties easily fall into a state of chronic fatigue, and it is often difficult to disentangle the psychological from the physical problems. In practice, cause and effect are hard to distinguish in cases of clinical fatigue. This may be caused by dislike of the occupation, of the immediate task, or of the workplace or, conversely, may itself be the cause of maladjustment to work or surroundings.

\section{MEASURING MENTAL FATIGUE}

The science of ergonomics is just as concerned with the quantitative measurement of fatigue as is industry itself. Science studies the relationships between the fatigue and the level of stress or, more accurately, fatigue and the output of work; in other words, the reaction of the human body to different stresses can be measured in order to develop ways of improving work and making it less laborious. The question asked by industry is often simply whether the working conditions make excessive demands on the operatives, or whether the stresses involved are physiologically acceptable.

One serious limitation is that to date there is no way of directly measuring the extent of the fatigue itself. There is no absolute measure of fatigue, comparable with that of energy consumption, expressed in kilocalories. All the experimental work carried out so far has merely measured certain manifestations or indicators of fatigue.

\section{Methods of measurement}

Methods currently used fall into six groups:

(1) quality and quantity of work performed;

(2) recording of subjective impressions of fatigue; 
(3) electroencephalography (EEG);

(4) measuring subjective frequency of flickerfusion of eyes;

(5) psychomotor tests;

(6) mental tests.

Measurements such as these are frequently taken before, during, and after the task is performed, and the extent of fatigue is deduced from them. As a rule the result has only relative significance, because it gives a value to be compared with that of a fresh subject, or at least with that of a control who is not under stress.

More recently it has been the practice to study a combination of several of the indicators, which are discussed below, in order to make interpretation of the results more reliable. It is particularly important that subjective feelings of fatigue should also be taken into account. Measurement of physical factors must be backed up by subjective assessment before it can be correctly assumed to indicate a state of fatigue.

\section{Quality and quantity of output}

The quality and quantity of output is sometimes used as an indirect way of measuring industrial fatigue. Quantity of output can be expressed as number of items processed, time per unit, or conversely, as the number of operations performed per unit time. Fatigue and rate of production are certainly interrelated to some extent, but the latter cannot be used as a direct measure of the former because there are many other factors to be taken into account, such as production targets, social factors and psychological attitudes to the work.

Sometimes fatigue must be considered in relation to the quality of the output (bad workmanship, faulty materials, outright rejects), or to the frequency of mistakes, once again with the reservation that fatigue is not the only variable factor.

\section{Subjective feelings}

Special questionnaires have been used to assess subjective feelings; these include the so-called bipolar questionnaires, which are very simple to handle and easy to interpret. Two opposing and mutually exclusive states are placed at opposite ends of a line $7 \mathrm{~cm}$ long, and the research subjects place a mark along the line to indicate how they assess these characteristics in themselves at that particular moment. This gives a quantitative value to the subjective feeling, although as a rule what is used is the difference between marks made at the beginning and end of the task.

The contrasting pairs of characteristics that give particularly sharp differences after hard work are the following:

$\begin{array}{ll}\text { fresh } & \text { weary } \\ \text { sleepy } & \text { wide awake } \\ \text { vigorous } & \text { exhausted } \\ \text { weak } & \text { strong } \\ \text { energetic } & \text { apathetic } \\ \text { dull, indifferent } & \text { ready for action } \\ \text { interested } & \text { bored } \\ \text { attentive } & \text { absent-minded }\end{array}$

Barmack (1939), Haider (1962), and Groll and Haider (1965) successfully used questionnaires of this type under industrial conditions. Other authors have suggested more complicated questionnaires, among them the comparison process of Pearson and Byars (1956), and the very comprehensive questionnaire used by Nitsch (1970).

\section{The electroencephalograph}

The electroencephalograph is particularly suitable for standardised research in the laboratory, where variations in the trace in the sense of increasing synchronisation (increase of $\alpha$ and $\theta$ rhythms, reduction of $\beta$ waves) are interpreted as indicating states of weariness and sleepiness (see Fig. 3). The techniques of detecting and recording have been improved recently, so that the electroencephalograph can now also be used successfully to monitor sedentary activities, such as driving a vehicle (O'Hanlon et al., 1975; Zeier and Bättig, 1977).

\section{Flicker-fusion frequency of the eye}

During the last 25 years the flicker-fusion frequency of the eye has been increasingly used as an indication of the degree of fatigue, as follows. The research subject is exposed to a flickering lamp, and its frequency is increased until the flickers appear to fuse into a continuous light. The frequency at which this occurs is called the subjective flicker-fusion frequency.

Some changes in the procedure have been proposed recently. With the improvements in technique it is possible, on the one hand, to reduce the spread of the measurements and, on the other, to make fairly sure that the research subjects are not being influenced by the investigator (Gierer et al., 1979).

It has been observed that reductions in the flickerfusion frequency of $0.5-6 \mathrm{~Hz}$ take place after mental stress, as well as under various industrial stresses. However, a survey of the literature shows that not every kind of stress brings about such a reduction. So far, experience has shown, by and large, that

(1) a distinct lowering of the flicker-fusion frequency can be expected during unbroken mental stress of a high level. Examples are calculating in one's head, working as a telephonist or as an air-traffic controller or carrying out demanding visual work. Furthermore dull 
repetitive and monotonous situations produce a distinct lowering of the flicker-fusion frequency;

(2) little, if any lowering results from work that requires only moderate mental effort, and which allows the operative comparative freedom of action, or which involves physical effort. Examples are office work, sorting jobs, and repetitive work at a moderate mental level.

Experience to date has encouraged most authors to interpret a lowering of the flicker-fusion frequency as a sign of fatigue. Hence, many authors think that this lowering is associated with a deactivation of the cerebral cortex (Hashimoto, 1969), but this is no more than a hypothesis, which must be tested by further experiment.

\section{Psychomotor tests \\ Psychomotor tests measure functions that involve perception, interpretation and motor reactions. The following tests are often used: \\ simple and selective reaction times; \\ tests involving tapping or pricking squares in a grid; \\ tests of skill; \\ driving tests under simulated conditions; \\ typing; \\ tachistoscopic tests to measure performance in- volving perception.}

Several examples of such test methods are described by Welford (1968). In tests like these, too, it is assumed that a falling-off of performance can be taken as a sign of a state of fatigue.

A disadvantage of psychomotor tests is that often the test itself makes heavy demands on the subject, thereby raising the level of cerebral activity. As previously discussed, it is very likely that such tests will cause some kind of cerebral activity, which may at least temporarily mask any possible signs of fatigue.

\section{Mental tests \\ Performance of mental tests often involves arith- metical sums, tests of concentration (such as crossing- out tests), estimation tests (such as estimation of time intervals), and memory tests. As in psycho- motor tests, the test itself may excite interest in the person being examined, and so cancel out any signs of fatigue. Other confusing factors are the effects of training and experience, and, if the test is protracted, fatigue brought on by the test itself.}

\section{Field studies on mental fatigue}

In recent decades more and more use has been made of fatigue studies carried out under industrial conditions, in traffic, in schools, and in various other everyday situations. As a rule their significance is limited to a particular problem in a particular setting, and very little can be deduced from them that is of wider application, or which would lead to generalisations about the relationship between stress and fatigue.

\section{MENTAL FATIGUE AND BOREDOM}

In field studies many authors do not distinguish between fatigue and boredom. They consider boredom to be a special type of fatigue because, in fact, boredom is certainly also caused by a reduction of the activation level of the brain.

It has been shown that a stream of impulses from the sensory organs, combined with feedback to the cerebral cortex, stimulate the reticular activating system, and that by this means the reactivity of the CNS (and hence of the whole body) is maintained in a high state of readiness.

When stimuli are few, the stream of sensory impulses dries up, bringing about a reduction in the level of activation of the cerebrum, and thereby of the functional state of the body as a whole (Fig. 5).

The physiological aspects of boredom may therefore be summarised as follows: situations which are characterised by a low level of stimulation, or by a regular repetition of identical stimuli, or just by making few mental or physical demands upon the operator, lead to a functional state of the central nervous system characterised by a reduction in the level of cerebral activation and accompanied by feelings of weariness and sleepiness, decreased vigilance, disinclination for the task and decline in alertness.

It is obvious that these symptoms are nearly the same as those for a state of fatigue. It is therefore understandable if many authors like Hashimoto (1969) make no fundamental distinction between fatigue and boredom, both of these conditions indicating a lowered activation level of the brain.

This concept is especially justified in field studies. Industrial practice is much more complex than a standardised laboratory experiment. In fact, both fatigue and boredom give ise to similar symptoms and the causes cannot be assessed.

Who can say, for example, whether the decline in performance, the rise in $a$ waves in the brain, and the tired feelings of truck drivers are signs of a fatigue state, or the effects of boredom? Who can say whether the monotonous, repetitive job of the bottle-watchers is just boring, or whether excessive demands on their vigilance are actually fatiguing? There are many examples of this kind, which show that situations often arise, both in industrial practice and in traffic conditions, which can be simultaneously boring and fatiguing. In such cases the distinction 
between these two states is purely arbitrary, and the most credible research is that which makes no attempt to draw one.

Some of the following field studies could be considered to be problems of fatigue as well as problems of boredom.

\section{A STUDY ON A PRODUCTION LINE}

In 1961, Haider studied fatigue among 337 female workers in textile factories, 207 of whom worked on a moving production line, while the other 130 worked individually. He assessed the subjective feelings of these workers by using a self-assessment card, with 12 pairs of contrasting states. Comparison of the two groups gave, on average, the following differences. The production line workers were more tense, bored and dreamy than those who worked at their own speed. Haider (1961) writes of these: 'finally we may conclude that when the occupation is a long succession of simple, repetitive acts, we may expect to see 'saturation phenomena', with increasing tension, restlessness, lack of incentive, and a declining performance of the boring work'. In fact, the percentage of discontented and tense workers on the production line was as high as $20-25 \%$. Haider (1963) also studied the actual physiological symptoms of boredom and fatigue among a selection of electronic workers, who were engaged in work that was both monotonous and time-linked. During their work these women were subjected to light signals, which appeared at irregular intervals on the protective shield of their machine. Each time they noticed a flash of light they were required to press a pedal, and in this way it was possible to monitor their level of alertness throughout the day, as well as their speed of response. The author found that the alertness of the 29 women workers declined during the working period, and their reaction time increased. Figure 7 shows part of these results.

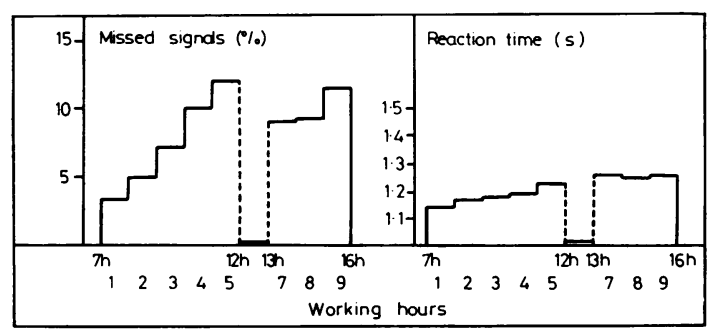

Fig. 7 Vigilance and readiness for action during repetitive and paced work. The curves express average values for 29 female operatives. Left: the percentage of signals missed; right: the simple reaction time in seconds. After Haider (1963).
In the course of a working shift the women workers missed more and more signals, as well as taking longer to react to the ones they did notice. It seems fair to assume that this decline in performance is a result of the monotonous, repetitive nature of the job.

\section{A STUDY IN THE FOOD INDUSTRY}

Saito and his colleagues (1972) carried out a major investigation in the food industry. The operatives studied were engaged in the visual control of bottles and their contents which moved so quickly that the job was rated as arduous, even though monotonous and repetitive. Even after a short time at work the number of rejected bottles became distinctly lower, a fact which the authors considered must indicate diminishing alertness. Concurrently a distinct fall in the flicker-fusion frequency could be recorded, accompanied by such subjective symptoms as increasing fatigue, sleepiness, headache, and a sense of time dragging. The fall in flicker-fusion frequency was greatest at times when the operative was observed to talk less to the others, and tended to doze, or even to fall asleep. The time-scale was as follows:

first hour-little change;

2nd-4th hours-strongly affected;

final hour before lunch-break-operatives both felt and performed better.

The authors had the opportunity to make comparable studies of a group of operatives whose work was more varied, and therefore less monotonous. This group showed less absenteeism and fewer subjective complaints.

\section{DRIVERS' FATIGUE}

Particular importance is attached to studies of fatigue in traffic, because it is reasonable to suppose that fatigue plays an important part in mistakes and accidents. Several authors have shown indisputably that about four hours of continuous driving is enough to bring on a distinct reduction in the level of alertness, and thereby to increase the risk of accidents. Thus Pin (1966), as well as Lecret and others (1968), observed a progressive increase of the $a$ waves in the electroencephalograms of drivers of motor vehicles, with a simultaneous increase in the rate of blinking, and a fall in heart rate.

Harris and others (1972) report that, after a few hours at the wheel, the performance of drivers of buses and of heavy lorries became distinctly poorer, especially their judgement of the edge of the road, and the necessary number of corrective movements of the steering wheel. Simultaneously, the variability of heart rate and a feeling of fatigue both increased, which the authors interpreted as signs of a fall in the level of cerebral activation. 
This confirms the results of O'Hanlon (1971), who found a distinctly higher heart-rate variability among drivers of motor vehicles after long test-drives. O'Hanlon interpreted the observed rise in variability as a sign of diminished alertness. Furthermore, the variability reverted to the normal value after a stop for rest, or after a street incident.

All these studies of driving fatigue may be summarised as follows. The first signs of fatigue appear after only a few hours' driving, and comprise diminished accuracy of driving, accompanied by a fall in the activation levels of the CNS (fall in heart rate, with greater heart-rate variability), a rise in the $a$ waves of the EEG, and more frequent blinking. The fall in activation level is accompanied by reduced alertness, sufficient to increase significantly the risk of accidents. This fall in activation level is especially marked in motorway driving, and at night. The degree of driving fatigue is determined by the combined effect of several factors, the most important of these being the extent and duration of mental stress, boredom, and circadian (day-night) rhythm.

\section{AIR-TRAFFIC CONTROLLERS}

We had the opportunity to carry out a large-scale study (Grandjean, 1970; Grandjean et al., 1971) of the air-traffic controllers at Zurich airport. The studies comprised an analysis of the work involved, measurements of indicators of fatigue, and an interrogation.

One group of air-traffic controllers spend their time watching the movements of aircraft on a radar screen, while at the same time they exchange information and instructions on the radio transmitter with the pilots and with other members of the control organisation.

Work analysis shows that a controller concentrates his attention on the radar screen for a total of $3.5 \mathrm{~h} / \mathrm{day}$, and that he passes on about $800 \mathrm{items}$ of coded information every day. The following were used as indicators of fatigue:

subjective flicker-fusion frequency;

a tapping test (maximum number of tapping movements in $10 \mathrm{~s}$ );

a grid-pricking test (maximum number of pricks in $10 \mathrm{~s}$ );

a bipolar questionnaire designed by Barmack (1939) for surveys of subjective impressions.

The tests took place nine times every $24 \mathrm{~h}$ at an average interval of $2.5 \mathrm{~h}$, extending over three weeks, and involving 68 controllers. Part of the result is shown in Figs. 8 and 9 as average values, in relation to the duration of the work. During the first six working hours the flicker-fusion frequency showed a drop of $0.5 \mathrm{~Hz}$, and afterwards fell more quickly
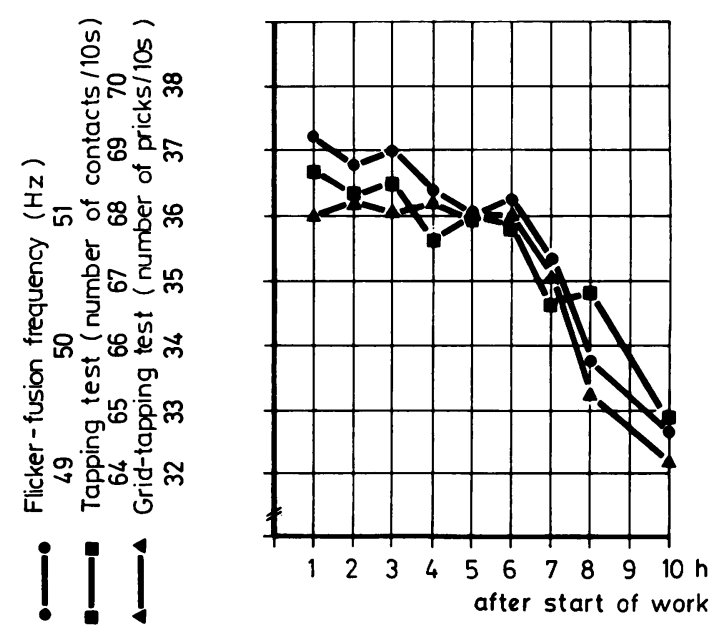

Number of subjects: $6765646666 \quad 6750$ 58

Fig. 8 Average values for the flicker-fusion frequency, and for two psychomotor tests of air-traffic controllers, in relation to the time elapsed since the start of their working shift (but unrelated to clock time). After Grandjean (1970), Grandjean and Wotzka (1971), and Grandjean et al. (1971).

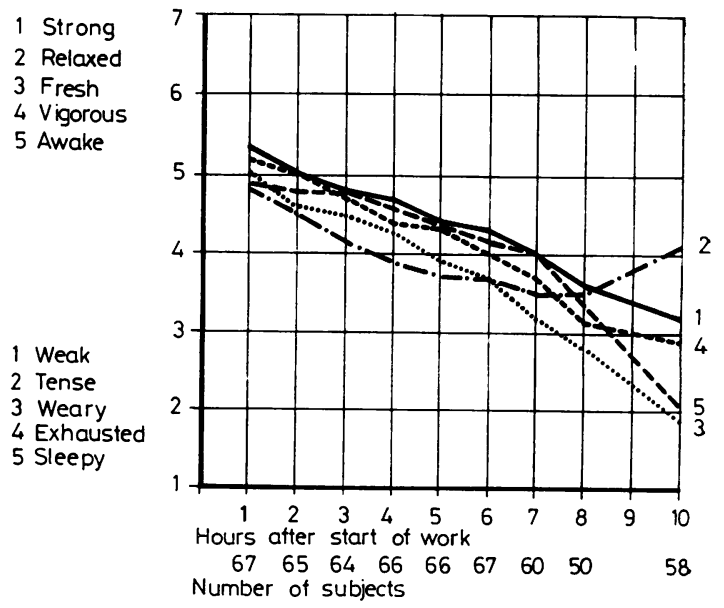

Fig. 9 Average values for self-assessed, subjective feelings of fatigue in relation to time elapsed since start of work (but unrelated to clock time) among air-traffic controllers. The ordinate represents a line $7 \mathrm{~cm}$ long, upon which the subjects have to indicate their position between the two extremes with the same number in the upper and lower lists. Ordinate No. 4 is the approximate neutral level between these extremes. After Grandjean (1970), Grandjean and Wotzka (1971), and Grandjean et al. (1971). 
until 10 hours of work, when the drop totalled $2 \cdot 3 \mathrm{~Hz}$. The psychomotor performance in tapping and pricking tests followed a similar course. All three psychomotor tests showed a moderate fall in the first six working hours, but after the seventh hour the drop became much steeper.

The sequence of subjective impressions shows first a gradual shift towards disinclination for action. The middle line (line 4) of the ordinate of Fig. 9 represents a neutral level between the two extremes of feeling, and all five of the emotional states are in this vicinity between the fourth and the seventh working hours (abscissa of graph). From then onwards the decline is particularly striking in the direction of sleepy (American Society of Heating, Refrigerating and Air-conditioning Engineers, 1972) and weary (Akerblom, 1948).

Comparison of the results in the two diagrams shows, therefore, a similar result: during the first 4-7 $\mathrm{h}$ there is only a moderate drop in readiness for action and in psychophysiological efficiency; after the seventh hour fatigue increases much more quickly, as shown by both obje:tive and subjective indicators.

These experimental results show that the occupation of air-traffic controller makes heavy demands on sustained alertness, and carries a heavy responsibility.

A comparison between these results for air-traffic controllers, and those for drivers of buses and heavy vehicles, obtained by O'Hanlon (1971), Harris et al. (1972), and Lecret (1976) shows interesting parallels. Both occupations call for sustained vigilance; in both cases the first signs of reduced efficiency appear after about four hours, and this becomes very marked after seven or eight hours. This decline is a symptom of a fatigue state, which shows itself in both groups as subjective fatigue, a fall in flickerfusion frequency, a decline in psychomotor efficiency and in driving precision, higher heart-rate variability, a fall in heart rate and a rise in the $a$ waves of the EEG. It is difficult to ignore the obvious assumption that all these symptoms are expressions of a decline in the level of activation (arousal) of the central nervous system.

One final conclusion is inevitable. Occupations that demand sustained vigilance must be so planned, with working periods and rest periods, that the risk of accidents is not increased through fatigue of the operators. The research work detailed above shows that these conditions are not being fulfilled at present.

\section{References}

Akerblom, B. (1948). Standing and Sitting Posture. Nordiska Bokhandeln: Stockholm.

American Society of Heating, Refrigerating and Airconditioning Engineers $(1967,1972)$. Handbook of Funda- mentals. ASHRAE: New York.

Barmack, J. E. (1939). The length of the work period and the work curve. Journal of Experimental Psychology, 25, 109115.

Bonvallet, M., Dell, P., and Hiebel, G. (1954). Tonus sympathique et activité électrique corticale. Journal of Electroencephalography and Clinical Neurophysiology, 6, 119-126.

Gierer, R., Martin, E., Baschera, P., and Grandjean, E. (1979). Ein Gerät zur Bestimmung der Flimmerverschmelzungsfrequenz des Auges. European Journal of Applied Physiology (in press).

Grandjean, E. (1970). Fatigue. Yant Memorial Lecture, 1970. American Industrial Hygiene Association Journal, 31, 401411.

Grandjean, E., and Wotzka, G. (1971). Correlations between subjective and physiological criteria of fatigue. In Proceedings of the 17th International Congress of the International Association of Applied Psychology, Liège, 1970, pp. 375-380. Editest: Bruxelles.

Grandjean, E., Wotzka, G., Schaad, R., and Gilgen, A. (1971). Fatigue and stress in air traffic controllers. Ergonomics, 14, 159-165.

Groll, E., and Haider, M. (1965). Belastungsunterschiede bei Arbeiterinnen in Früh- und Spätschicht. Internationale Zeitschrift für angewandte Physiologie einschliesslich Arbeitsphysiologie, 21, 305-309.

Haider, M. (1961). Direkte und indirekte Selbsteinstufungen der Auswirkungen von freier Arbeit und von Fliessbandarbeit. Psychologie und Praxis, 5, 1-11.

Haider, M. (1962). Ermüdung, Beanspruchung und Leistung. Franz Deuticke: Wien.

Haider, M. (1963). Experimentelle Untersuchungen über Daueraufmerksamkeit und Cerebrale Vigilanz bei einförmigen Tätigkeiten. Zeitschrift für experimentelle und angewandte Psychologie, 10, 1-18.

Harris, W., Mackie, R. R., Abrams, C., Buckner, D. N., Harabedian, A., O'Hanlon, J. F., and Starks, J. R. (1972). A Study of the Relationship among Fatigue, Hours of Service and Safety of Operations of Truck- and Bus-drivers. Report No. 1727-2. Human Factors Research Inc., Santa Barbara, Goleta, California 93017.

Hashimoto, K. (1969). Physiological features of monotony manifested under high speed driving situations. In Proceedings of the 16th International Congress of Occupational Health, Tokyo, pp. 85-88. Railway Labour Science Institute, Japan National Railways.

Jasper, J. J. (1941). In Epilepsy and Cerebral Localisation. Edited by Penfield and Erickson. C. C. Thomas: Illinois. Cited in Ganong, W. F. (1974). Lehrbuch der Medizinischen Physiologie, p. 151. Springer Verlag: Berlin.

Lecret, F. (1976). La fatigue du conducteur. Cahiers d'étude de l'Organisme National de Sécurité Routière (ONSER). Bulletin No. 38. ONSER: Paris.

Lecret, F., Pin, M. C., Cura, J. B., and Pottier, M. (1968). Les variations de la vigilance au cours de la conduite sur autoroute. In 6me Congrès de la Société Ergonomique de Langue Française (SELF), Paris.

Legendre, R., and Piéron, H. (1913). Zitiert nach Pappenheimer (Sleep promoting effects of cerebrospinal fluid from sleep-deprived goats). Zeitschrift für allgemeine Physiologie, 14, 235.

Nitsch, J. (1970). Theorie und Skalierung der Ermüdung. PhD thesis. University of Cologne.

O'Hanlon, J. F. (1971). Heart Rate Variability; a New Index of Drivers' Alertness/Fatigue. Report No. 1812-1. Human Factors Research Inc., Santa Barbara, Goleta, California 93017.

O'Hanlon, J. F., Royal, J. W., and Beatty, J. (1975). EEG theta Regulation and Radar Monitoring Performance in a Controlled Field Experiment. Technical Report No. 
1738-F. Human Factors Research Inc., Santa Barbara, Goleta, California 93017.

Pappenheimer, J. R., Miller, T. V., and Goodrich, C. A. (1967). Sleep-promoting effects of cerebrospinal fluid from sleep-deprived goats. Proceedings of the National Academy of Sciences of the United States of America, 58, 513-518.

Pearson, R. G., and Byars, G. E. (1956). The Development and Validation of a Checklist for Measuring Subjective Fatigue. Report 56-115. School of Aviation Medicine, USAF, Randolph AFB, Texas.

Pin, M. C. (1966). Application des techniques electrophysiologiques à l'étude des la conduite automobile. Cahiers d'étude de l'Organisme National de Sécurité Routière (ONSER). Bulletin No. 15. ONSER: Paris.
Saito, H., Kishida, K., Endo, Y., and Saito, M. (1972). Studies on bottle inspection task. Journal of Science of Labour, 48, 475-525.

Scherrer, J. (1967). Physiologie musculaire. In Physiologie du Travail, pp. 1-42. Edited by J. Scherrer. Masson: Paris.

Welford, A. T. (1968). Fundamentals of Skill. Methuen: London.

Yllö, A. (1962). The biotechnology of card-punching. Ergonomics, 5, 75-79.

Zeier, H., and Bättig, K. (1977). Psychovegetative Belastung und Aufmerksamkeitsspannung von Fahrzeuglenkern auf Autobahnabschnitten mit und ohne Geschwindigkeitsbegrenzung. Zeitschrift für Verkehrssicherheit, 23, 1. 